\title{
Context-Dependent Memory for Meaningful Material: Information for Students
}

\author{
HARRY M. GRANT, LANE C. BREDAHL, \\ JOHN CLAY, JENNIFER FERRIE, JANE E. GROVES, \\ TIMOTHY A. McDORMAN and VERONICA J. DARK*
}

Iowa State University, USA

\begin{abstract}
SUMMARY
Context-dependency effects on memory for lists of unrelated words have been shown more often with recall than with recognition. Context dependency for meaningful text material was examined using two standard academic testing techniques: short answer (recall) and multiple choice (recognition). Forty participants read an article in either silent or noisy conditions; their reading comprehension was assessed with both types of test under silent or noisy conditions. Both tests showed context-dependency effects in which performance was better in the matching conditions (silent study/silent test and noisy study/noisy test) than in the mismatching conditions (silent study/noisy test and noisy study/silent test). Context cues appear to be important in the retrieval of newly learned meaningful information. An academic application is that students may perform better on exams by studying in silence. (C) 1998 John Wiley \& Sons, Ltd.
\end{abstract}

Appl. Cognit. Psychol. 12: 617-623 (1998)

Environmental context-dependency effects occur when there is better performance on a memory test when the test occurs in the same environment in which the to-beremembered material was originally studied (the matching condition) than when the test occurs in a different environment (the mismatching condition). The literature contains many instances of context-dependency effects for recall (e.g. Godden and Baddeley, 1975; Jerabek and Standing, 1992; Martin and Aggleton, 1993; McDaniel et al., 1989; Smith, 1979; Smith, Standing and de-Man, 1992; see Smith, 1988, for a comprehensive review; see Fernandez and Glenberg, 1985, for exceptions). Context-dependency effects for recall memory are typically interpreted as showing that the characteristics of the environment are encoded as part of the memory trace and can be used to enhance retrieval of the other information in the trace (e.g. Eich, 1980; Smith, 1988).

Context-dependency effects for recognition also have been found (e.g. Canas and Nelson, 1986; Smith, 1985, 1986; Smith and Vela, 1992), but the literature contains mixed results in that many studies do not show such effects (e.g. Bell et al., 1984; Godden and Baddeley, 1980; Smith, Vela and Williamson, 1988). The fact that context-dependency effects are more easily obtained with recall tests than with recognition tests has been used to suggest that there are differences in the retrieval processes

*Correspondence to: Veronica J. Dark, Department of Psychology, Iowa State University, Ames, IA 50011-3180, USA. 
involved in the two types of tests. Smith's (1988) 'outshining' hypothesis, for example, suggested that recognition items themselves act as such strong retrieval cues (copy cues) that they overshadow, or outshine, the relatively weak contribution of environmental context cues. Smith (1986) suggested that conditions emphasizing more meaningful encoding might mask any effects of environmental context at test even for recall, because such encoding would produce retrieval cues that would outshine context as a retrieval cue (also see McDaniel et al., 1989).

Although Smith's (1988) review pointed out that most of the research assessing context-dependency effects have used lists of unrelated words as the to-be-remembered material, the review included five studies that examined the effect of changing classrooms on exam performance. Only one published study (Metzger et al., 1979) reported that switching rooms harmed performance while three published studies (Abernethy, 1940; Farnsworth, 1934; Saufley, Otaka and Bravaresco, 1986) reported that it did not. Smith noted, however, that students actually study for exams in many different environments, so that there was a potential mismatch between study and test context even when students were tested in their regular classroom and that an unpublished study (Mellgren, 1984), which did control both the study and test environments, showed context dependency. Thus, Smith (1988) concluded that the extent to which environmental context affected retrieval of meaningful material was unresolved.

We were interested in determining whether environmental context-dependency effects would be found with the type of material and the type of tests typically encountered in school. For practical reasons, our focus was more on study conditions than on differences in classroom testing conditions: Students have more control over their study environments than over their test environments. It was our collective observation that many high school and college students study material in environments very different from those in which they are tested. The study environments often include background music or background noise from either family, friends, or television, while the test environments are typically quieter. If context dependency occurs with meaningful course material, then students' study habits could be harming their test performance.

We chose to manipulate the presence or absence of general background noise rather than to manipulate the presence or absence of background music, because people vary widely in the type of music they prefer. To distinguish between contextdependency effects and the possibility that background noise simply interferes with encoding (see Bell et al., 1984), a factorial design was used in which both the study context and the test context were varied. Participants read a two-page article under silent or noisy conditions and were then tested under matching or mismatching conditions. The tests were designed to mimic standard classroom tests, and thus assessed comprehension of new material (i.e. memory for meaning), rather than verbatim memory of what was studied. Because of the possibility that context-dependency effects might differ with different types of tests, participants completed both a shortanswer recall test and a multiple-choice recognition test.

\section{METHOD}

\section{Participants}

Eight members of a psychology laboratory class served as experimenters. Each experimenter recruited five acquaintances to serve as participants. There were 39 participants, 
ranging in age from 17 to 56 years $(M=23.4, \mathrm{SD}=5.9)$, and there were 17 females and 23 males.

\section{Design}

Study context (silent versus noisy) and test context (silent versus noisy) were manipulated in a between-subjects factorial design, producing four conditions. Each experimenter ran one participant for each of the four conditions and an additional participant for one of the conditions as assigned by the instructor. Experimenters randomly assigned their participants to their five conditions.

\section{Stimuli}

Each experimenter provided his or her own cassette tape player and headphones. The eight cassettes were exact copies made from a master tape of background noise recorded during lunchtime in a university cafeteria. Care was taken to prevent complete sentences from being audible; thus the background noise consisted of occasional distinct words or phrases embedded within a general conversational hum that was intermixed with the sounds produced by movement of chairs and dishes. The tape was played at a moderately loud level.

An article on psychoimmunology (Hales, 1984) was selected as the to-be-studied material. It was judged by the experimenters to be interesting and understandable. The article was two pages in length with three columns of text to a page.

Sixteen multiple-choice questions, each consisting of a stem and four alternatives, were generated. All questions tested memory for points stated in the text (i.e. no inferences were required). Although a stem or correct alternative sometimes were taken verbatim from the article, in most cases the stem and correct alternative together were a close paraphrase of a main point presented in a paragraph. Ten shortanswer questions were derived from those multiple-choice stems that could be easily restated to produce a question that could be answered unambiguously by a single word or phrase. The order of the questions on each test followed the order in which the tested points were made in the text. The short-answer test was always administered first to ensure that recall of information from the article was being tested and not recall of information from the multiple-choice test.

\section{Procedure}

The instructions, which were read aloud, described the experiment as a class project and stated that participation was voluntary. Participants were asked to read the article through one time as if they were reading it for a class assignment; they were allowed to highlight and underline as they read. Participants were informed that their comprehension would be tested with both a short-answer test and a multiple-choice test.

All participants wore headphones while they read. Participants in the silent condition were told they would not hear anything over the headphones, and participants in the noisy condition were told that they would hear moderately loud background noise over the headphones but that they should ignore it. Reading time was recorded by the experimenter. A break of approximately 2 minutes between the end of the study phase and the beginning of the test phase was incorporated to 
minimize recall from short-term memory; participants typically rested without headphones during this interval.

The short-answer test was given first and was followed by the multiple-choice test. Participants were tested in either silent or noisy conditions and were informed of the condition before testing began. Regardless of testing condition, all participants wore headphones. At the end of testing, participants were debriefed concerning the purpose of the experiment. The entire procedure lasted about 30 minutes.

\section{RESULTS}

An alpha level of 0.05 was used for all analyses. Mean reading time and performance on each test are shown in Table 1. The data from one person in the silent study/silent test condition were omitted from the analysis because his performance was over 2.5 standard deviations below the combined group mean on each test.

\section{Reading time}

An analysis of variance performed on the mean number of minutes taken to read the article with study condition (silent and noisy) and test condition (silent and noisy) as between-subjects variables did not show any reliable effects (all $F \mathrm{~s}<1.00$ ). Although the results suggest that participants in all groups spent roughly equal amounts of time studying the material, there was considerable individual variability. Therefore, reading time was used as a covariate in the analyses of test performance.

\section{Short-answer test}

An analysis of covariance on the mean number of items (out of 10) correctly answered on the short-answer test with study condition and test condition as between-subjects

Table 1. Mean reading time (in minutes) and mean number correct on the two tests as a function of study condition and test condition

\begin{tabular}{|c|c|c|c|c|}
\hline \multirow[b]{3}{*}{ Test condition } & \multicolumn{4}{|c|}{ Study condition } \\
\hline & \multicolumn{2}{|c|}{ Silent } & \multicolumn{2}{|c|}{ Noisy } \\
\hline & $M$ & SD & $M$ & SD \\
\hline \multicolumn{5}{|l|}{ Reading time } \\
\hline Silent & 15.0 & 7.08 & 13.8 & 6.78 \\
\hline Noisy & 11.8 & 3.07 & 14.0 & 8.24 \\
\hline \multicolumn{5}{|c|}{ Short-answer test ${ }^{\mathrm{a}}$} \\
\hline Silent & 6.7 & 1.22 & 5.4 & 1.90 \\
\hline Noisy & 4.6 & 1.17 & 6.2 & 2.20 \\
\hline \multicolumn{5}{|c|}{ Multiple-choice test ${ }^{\mathrm{b}}$} \\
\hline Silent & 14.3 & 1.58 & 12.7 & 1.64 \\
\hline Noisy & 12.7 & 1.64 & 14.3 & 1.77 \\
\hline
\end{tabular}

aThe maximum possible was 10 .

bThe maximum possible was 16 .

Note. The silent study/silent test condition had 9 participants. All other conditions had 10 participants. 
variables and reading time as the covariate showed no effect of the covariate and no main effect of either study or test condition (all $F \mathrm{~s}<1.25$ ). There was a reliable Study Condition $\times$ Test Condition interaction $(F(1,34)=6.53, M S E=2.95)$. A planned contrast comparing performance in the matching conditions (silent study/silent test and noisy study/noisy test) to performance in the mismatching conditions (silent study/noisy test and noisy study/silent test) was reliable $(F(1,34)=6.79)$ and the residual sum of squares from the combined treatment and interaction effects was not $(F(2,34)=1.08)$.

\section{Multiple-choice test}

A parallel analysis of covariance on the mean number of items (out of 16) correctly answered on the multiple-choice test showed no effect of the reading time covariate and no main effect of either study or test condition (all $F \mathrm{~s}<1.00$ ). There was a reliable Study Condition $\times$ Test Condition interaction $(F(1,34)=9.11, M S E=2.82)$. The same contrast comparing matching and mismatching conditions that was applied to the short-answer results was applied post hoc to the multiple-choice results. The contrast was reliable $(F(1,34)=9.00)$ and the residual sum of squares from the combined treatment and interaction effects was not $(F<1.0)$.

\section{DISCUSSION}

This research was designed to test whether memory for the type of meaningful prose that is presented in many academic courses would show the kind of contextdependency effect that often has been reported for recall, but not recognition, of unrelated lists of words (see Smith, 1988). The results showed that there are contextdependency effects for newly learned meaningful material regardless of whether a short-answer test or a multiple-choice test is used. For both types of test, studying and testing in the same environment (the matching conditions) was more beneficial. Because the testing conditions in academic settings are relatively quiet, a practical suggestion based on the current results is that students are likely to perform better on exams if they study for them with a minimum of background noise.

Smith (1986) suggested that situations involving the higher cognitive processing of more complex material would likely be associated with little or no context dependency, but his conclusions were based on studies that examined memory for unrelated word lists. The current research, which examined memory for prose, suggests otherwise. Martin and Aggleton (1993) also showed context-dependency for learning new meaningful material. Novice scuba students spent 10 minutes reading instructions on how to use decompression tables either underwater in a pool or sitting in full gear on the edge of the pool. Testing consisted of actually using the tables and it occurred in the matching or the mismatching environment. The results were the same as those reported here; that is, there was strong context dependency. It appears that environmental context may be important in the retrieval of newly learned, meaningful material.

Smith (1988) pointed out that context-dependency effects in recognition are not found as consistently as in recall. The current results showed context dependency on a recognition test that was designed to tap encoding of meaningful prose. Recognition 
of meaning is likely a very different process than the recognition of the occurrence of a known word on a list of unrelated words. Dalton (1993) made a related point about the recognition of faces. She found environmental context dependency in the recognition of unfamiliar faces, but not in the recognition of familiar faces (see also Davies, 1988). Environmental context may be more important for recognition of newly learned meaningful material than for the recognition of familiar stimuli.

There was no overall main effect of noise on performance, supporting the claims of many students that background noise does not interfere with their study. However, the fact that there was evidence for context dependency suggests that students are better off studying without such background noise because it will not be present during the test. Although this research did not examine the impact that studying to music might have on a later test, to the extent that the music simply provides background noise that is ignored, the same context-dependency effects should be observed.

\section{AUTHOR'S NOTE}

The first six authors were students in an upper-division laboratory class taught by Veronica J. Dark. Except for the first author, they are listed in alphabetical order. Collin Paige and Cherine Abdalah also participated in the project as members of the class.

\section{REFERENCES}

Abernethy, E. M. (1940). The effects of changed environmental conditions upon the results of college examinations. Journal of Psychology, 10, 293-301.

Bell, P. A., Hess, S., Hill, E., Kukas, S. L., Richards, R. W. and Sargent, D. (1984). Noise and context-dependent memory. Bulletin of the Psychonomic Society, 22, 99-100.

Canas, J. J. and Nelson, D. C. (1986). Recognition and environmental Context: the effects of testing by phone. Bulletin of the Psychonomic Society, 24, 407-409.

Dalton, P. (1993). The role of stimulus familiarity in context-dependent recognition. Memory \& Cognition, 21, 223-234.

Davies, G. M. (1988). Faces and places: Laboratory research on context and face recognition. In G. M. Davies and D. M. Thomson (Eds), Memory in context: Context in memory (pp. 35-53). New York: Wiley.

Eich, J. E. (1980). The cue-dependent nature of state-dependent retrieval. Memory \& Cognition, 8, 157-173.

Eich, J. E. (1985). Context, memory, and integrated item/context imagery. Journal of Experimental Psychology: Learning, Memory, and Cognition, 11, 764-770.

Farnsworth, P. R. (1934). Examinations in familiar and unfamiliar surroundings. Journal of Social Psychology, 5, 128-129.

Fernandez, A. and Glenberg, A. M. (1985). Changing environmental context does not reliably affect memory. Memory \& Cognition, 13, 333-345.

Godden, D. and Baddeley, A. (1975). Context-dependent memory in two natural environments: On land and under water. British Journal of Experimental Psychology, 66, 325-331.

Godden, D. and Baddeley, A. (1980). When does context influence recognition memory? British Journal of Experimental Psychology, 71, 99-104.

Hales, D. (1984). Psycho-immunity. In M. G. Walraven and H. E. Fitzgerald (Eds), Annual editions: Psychology 84/85 (pp. 225-226). Sluice Dock, CT: Dushkin.

Jerabeck, I. and Standing, L. (1992). Imagined test situations produce contextual memory enhancement. Perceptual and Motor Skills, 75, 400. 
Martin, K. M. and Aggleton, J. P. (1993). Contextual effects on the ability of divers to use decompression tables. Applied Cognitive Psychology, 7, 311-316.

McDaniel, M. A., Anderson, D. C., Einstein, G. O. and O'Halloran, C. M. (1989). Modulation of environmental reinstatement effects through encoding strategies. American Journal of Psychology, 102, 523-548.

Mellgren, R. L. (April 1984). The classroom as context. Paper presented at the Meeting of the Southwestern Psychological Association, New Orleans, LA.

Metzger, R. L., Boschee, P. F., Haugen, T. and Schnobrich, B. L. (1979). The classroom as learning context: Changing rooms affects performance. Journal of Educational Psychology, 71, 440-442.

Saufley, W. H., Jr, Otaka, S. R. and Bravaresco, J. (1986). Context effects: Classroom tests and context independence. Memory \& Cognition, 13, 522-528.

Smith, D. G., Standing, L. and de-Man, A. (1992). Verbal memory elicited by ambient odor. Perceptual and Motor Skills, 74, 339-343.

Smith, S. M. (1979). Remembering in and out of context. Journal of Experimental Psychology: Human Learning and Memory, 5, 460-471.

Smith, S. M. (1985). Environmental context and recognition memory reconsidered. Bulletin of the Psychonomic Society, 23, 173-176.

Smith, S. M. (1986). Environmental context-dependent recognition memory using a shortterm memory task for input. Memory \& Cognition, 14, 347-354.

Smith, S. M. (1988). Environmental context-dependent memory. In G. M. Davies and D. M. Thomson (Eds), Memory in context: Context in memory (pp. 13-34). New York: Wiley.

Smith, S. M. and Vela, E. (1992). Environmental context-dependent eyewitness recognition. Applied Cognitive Psychology, 6, 125-139.

Smith, S. M., Vela, E. and Williamson, J. E. (1988). Shallow input processing does not induce environmental context-dependent recognition. Bulletin of the Psychonomic Society, 26, $537-540$. 
Copyright of Applied Cognitive Psychology is the property of John Wiley \& Sons Inc. and its content may not be copied or emailed to multiple sites or posted to a listserv without the copyright holder's express written permission. However, users may print, download, or email articles for individual use. 